lie four large natural storage reservoirsLakes Erie, Huron, Michigan and Superior. So the flow of the Niagara River is almost constant, and must have been so for several thousand years at least. To be sure, sometimes westerly winds can drive the water of Lake Erie towards the entrance to the Niagara causing a 50 per cent increase in flow; but this is negligible as rivers go. The flow of the Ohio River, for example, varies by a factor of 313 within the year.

And the Great Lakes control not only the flow of water but also the sediment content. The only sediment carried by the Niagara over Horseshoe Falls is that picked up downstream of Lake Erie; and that is very little indeed. Moreover, the river flows through a plain except close to the Horseshoe Falls where, on the Canadian side, the ground rises to about 150 feet above the crest. As a result, the crest of the Falls has remained at about the same elevation throughout its retreat up the Upper Great Gorge. In short, the Niagara is an almost sediment-free river of almost uniform flow which falls over a crest of constant height.

All of which suggests that the rate of regression of the Horseshoe Falls as a result of erosion should have been more or less constant for about 4,200 years, or since the carving of the Upper Great Gorge began. Yet as Philbrick points out (Bull. Geol. Soc. Amer., 81, 3723; 1970), historical surveys made since 1842 show the rate of regression to have been very variable. Why should this be so ? To explain it Philbrick looks to the curious bottom profile along the Upper Great Gorge. Recent surveys have shown the river bottom to be a series of basins, or plunge pools, which are progressively lower in elevation in the upstream direction. In a constant geological environment and with a uniform flow of water, the only conceivable reason for a series of well defined plunge pools would be a series of near-zero regression rates. In other words, the Niagara Falls must have remained more or less stationary for certain periods (during which the plunge pools formed) between which the regression rate was comparatively high. And this must have been going on not only since 1842 but for thousands of years.

From an examination of historical descriptions and sketches of the Horseshoe Falls, and by comparing Niagara with other falls in New York State, Philbrick concludes that the rate of regression of the fall crest is critically dependent on the crest's shape. When it is in the form of a horizontal arch (U-shaped), as the Horseshoe crest is today, the rate of erosion is very slow. But when a V-shaped notch develops in the arch the erosion speeds up. In this sense the horizontal arch is the much more stable configuration; and the accompanying lack of regression gives the plunge pools time to form. The horizontal arch is not perfectly stable, however, because of jointing in the crestal rocks. If one of the slabs formed by the joints happens to break away, a notch quickly develops and the rate of normal erosion increases until the crest returns to the arched form.

All this suggests, of course, that the reasons for the variable regression rate are neither strictly geological nor hydrological. So Hubbard (quoted by Philbrick) has carried out a photoelastic study of laboratory models of the Horseshoe crest configuration in 1819 (a deeply notched arch as shown in an early painting by Van der Lyn) and 1966 (a broad arch). This clearly shows that the stresses at the apex of the 1819 notch are about three times as great as those at the equivalent point of the 1966 arch. Because higher stresses will lead to faster erosion under the constant flow of water, the laboratory evidence clearly confirms Philbrick's field deductions.

Philbrick's work is not only of academic interest but is part of a very practical programme to find ways of halting the erosion of the various falls in the Niagara area. Which is a pity. It would be nice to think that the Horseshoe Falls will go on retreating from the brash commercialism which currently surrounds this otherwise beautiful natural phenomenon.

\section{Electric Fields after Lightning}

THE enhancement of the Earth's electric field associated with lightning flashes was first studied and discussed as long ago as 1920 and a number of different recovery mechanisms have been proposed. Illingworth and Wormell publish the latest contribution to this topic in next Monday's Nature Physical Science and they are able to make several fairly definitive conclusions about the recovery mechanisms. They measured the field recoveries after 672 lightning flashes seen at Cambridge, and found that their results fell naturally into two categories in which the field changes were greater or less than $1,000 \mathrm{~V} \mathrm{~m}^{-1}$.

C. T. R. Wilson was the first to point out that the field recovery seemed to be approximately exponential after a flash; he suggested that there were two alternative explanations, one of which required a constant cloud charging current (after the flash) accompanied by a dissipation current proportional to the total thundercloud charge. His alternative idea was that the charging current might reduce as the charge on the cloud grew (Phil. Trans. Roy. Soc., A, 221, 73; 1920). More recently, Holzer and Saxon ( $J$. Geophys. Res., 57, 207; 1952) have found that the field of a charged thundercloud is profoundly modified by an atmosphere whose conductivity varies

\section{ARACHNIDS} Files and Scrapers

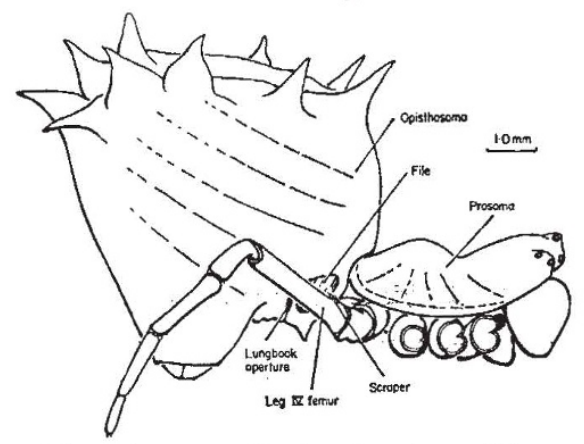

Micrathena gracilis showing the position of the stridulatory file and scraper (from J. Zool., 162, 482; 1970).

INCESSANT chirpings of crickets are familiar sounds in the heat of a dry summer's day. The sound, called stridulation, is characteristic of members of the insect family Orthoptera (although it is also found in certain other insects), and is produced by the rubbing together of certain modified surfaces. In the cricket, for example, each modified forewing or tegmen bears a rasping organ or file and a hardened area or scraper, and these structures are worked backwards and forwards against each other thus vibrating the specialized resonance area of another part of the tegmen. exponentially with height and that, at a distance of about $30 \mathrm{~km}$ from a storm, the size of the field due to the resulting space charge is about 90 per cent of that of the cloud itself. Illingworth and Wormell explain their recovery data by considering the response of the space charge to the lightning induced field changes.

One of their parameters is $T^{\prime}$, the time (s) for the field to recover to half its maximum value, taking the field before the flash to be zero. They found that for events in the first category the field change, $E$, and the time, $T^{\prime}$, were uncorrelated and some of the recoveries were rather irregular. They explained these findings along the lines of Wilson's first proposal but invoked a dissipation mechanism controlled by the clear air conductivity at the height of the cloud (a variable from one cloud to another). One of their chief conclusions is that for flashes closer than about $10 \mathrm{~km}$ the effects of the space charge are small but that for flashes at greater distances the recovery of the field measured at the ground can be well explained by the rearrangement of space charge in the vicinity of the storm. Their findings are based on numerical modelling and the fitting of their theoretical predictions to the experimental curves. 